\title{
ROBOTS CONTROL BASED ON PARAMETER IDENTIFICATION AND ADAPTIVE GAIN SMOOTH SLIDING OBSERVER-CONTROLLER
}

\author{
A. FILIPESCU ${ }^{1,2^{*}}$, L. DUGARD ${ }^{2}$, S. STAMATESC ${ }^{3}$ \\ ${ }^{1}$ University "Dunarea de Jos" of Galati, Department of Automation Applied Informatics \\ and Electronics, Domneasca,no.47,800008,Galati,Romania, Adrian.Filipescu@ugal.ro \\ ${ }^{2}$ Laboratoire d'Automatique Grenoble, CNRS/INPG UMR 5528, ENSIEG-BP 46, \\ 38402 Saint Martin d'Hères, Cedex, France,LLuc.Dugard@,inpg.fr \\ ${ }^{3}$ ASTI Control S.A, Calea Plevnei, 139, Bucharest, Romania, Sabin@asticontrol.ro
}

\begin{abstract}
An adaptive gain, smooth sliding observer-controller is developed to control $n$-degree of freedom rigid robotic manipulators with uncertain parameters. Furthermore, an on-line closed loop identification scheme, for time-varying parameters is proposed in order to obtain useful information despite loads, external disturbances and faults detection. In order to reduce the chattering, a smooth switching function (parameterised tangent hyperbolic function) is used instead of pure relay one, in the observer and the controller. The gains of the switching functions are adaptively updated, depending on the estimation and tracking errors, respectively. Using adaptive gains, the transient and tracking responses are improved. Simulation results with a two degree of freedom (DOF) robot manipulator are presented to show the interest of the approach. Copyright (C) 2005 IFAC
\end{abstract}

Keywords: Robotic manipulators, adaptive gain, smooth sliding observer-controller, parameter identification.

\section{INTRODUCTION}

State and parameter uncertainties in rigid robotic manipulators models, considered as MIMO nonlinear systems, as well as external disturbances lead to some problems in parameter identification and state estimation. All that necessitates to design the controller and/or the observer such that the closed loop robustness is achieved, i.e., stability with small tracking and estimation errors. It is well known that robustness to model parameter uncertainties and external disturbances can be achieved with a slidingmode controller. Indeed, maintaining the system on a sliding surface weakens the effect of the uncertainties in the closed loop performances and quickly leads to an equilibrium point. In Filipescu et al. (2003), an adaptive variable structure control with an ad hoc switching function (parameterized tangent hyperbolic denoted $k$-tanh) with adaptive modifications of its magnitude (denoted as $\lambda$-modification) is used, instead of a pure relay one with constant gain. In this paper, also, the parameterized tangent hyperbolic function is used as a switching function in order to alleviate or/and eliminate chattering. Decreasing the $k$ parameter in the switching function makes the gain around zero smaller and the unmodelled dynamics do have weak influence in high frequency. The input output delay due to the control input computation and the finite rate of switching can lead to chattering. Using the $\lambda$-modification in the $k$-tanh switching function gain, smoothes the response and increases the robustness to structural uncertainties. The adaptive gain is time depending and the norm of the corresponding sliding surface is an input. Based on a time-varying parameters identification technique, presented in $\mathrm{Xu}$ and Hashimoto (1993), $\mathrm{Xu}$ and Hashimoto (1996) and Xu, Pan and Lee (2003), the scheme is extended by introducing the observer, smooth switching function and the adaptive gain. It is then applied to a general robotic manipulator model. The physical robot may have gears and clutches inside the joint, and the torque supplied by the DC motor is transmitted to move the link. For this reason, a general robot manipulator model is considered. A sliding-mode observer-controller based on Sanchis and Nijmeijer (1998) is proposed. Extensions of sliding-mode control to MIMO non-linear uncertain systems have been made in Khalil (1996) and Utkin (1992). Several applications of the variable structure control to robot manipulators point out the robustness w.r.t. uncertainties and external disturbances of the closed loop (Slotine \& Sastry, 1983; Canudas de Wit $\&$ Slotine, 1991). With the $k$-tanh switching function and the $\lambda$-modification in the observer-controller 
gains, the closed loop behaves like an approximate sliding mode, in the neighbourhood of the corresponding sliding surface.

The main contributions of this paper are as follows: the adaptive smooth sliding observer-controller, the updating law of the variable structure gains, and finally, the identification of the time-varying parameters and external disturbances.

\section{ADAPTIVE GAIN SMOOTH SLIDING OBSERVER}

A very general robot manipulator model can be expressed as a square non-linear MIMO model

$\dot{\mathrm{x}}_{1}=\mathrm{x}_{2}, \quad \mathrm{x}_{1} \in \mathfrak{R}^{\mathrm{n}}$,

$\dot{\mathrm{x}}_{2}=\mathrm{h}\left(\mathrm{x}_{1}, \mathrm{p}\right)^{-1}\left[\mathrm{f}\left(\mathrm{x}_{1}, \mathrm{x}_{2}, \mathrm{p}\right)+\mathrm{g}\left(\mathrm{x}_{1}, \mathrm{x}_{2}, \mathrm{p}\right) \mathrm{u}\right]$,

$\mathrm{y}=\mathrm{x}_{1}, \quad \mathrm{p} \in \mathfrak{R}^{\mathrm{n}_{\mathrm{p}}}, \quad \mathrm{x}_{2} \in \mathfrak{R}^{\mathrm{n}} \quad \mathrm{u} \in \mathfrak{R}^{\mathrm{n}}$

where $\mathrm{x}_{1}$ is the only vector available for measurement, $\mathrm{u}$ and $\mathrm{y}$ are control input and measured output, respectively. The state space dimension is $2 n$ and $\mathrm{x}=\left[\begin{array}{ll}\mathrm{x}_{1}^{\mathrm{T}} & \mathrm{x}_{2}^{\mathrm{T}}\end{array}\right]^{\mathrm{T}} \in \mathfrak{R}^{2 \mathrm{n}}$ is the state vector. The unknown time-varying parameter vector $p \in \mathfrak{R}^{\mathrm{n}_{\mathrm{p}}}$ is supposed to be bounded. The function matrices $\mathrm{f}$, $\mathrm{g}$ and $\mathrm{h}$ may be partially unknown, with some parameter uncertainties. If one assumes the partial knowledge of the model parameters, state estimates, time-varying parameters and disturbances, one can define $\hat{f}=f\left(x_{1}, \hat{x}_{2}, \hat{p}\right), \hat{g}=g\left(x_{1}, \hat{x}_{2}, \hat{p}\right)$ and $\hat{h}=h\left(x_{1}, \hat{p}\right)$ as the estimates of the functions $f$, $g$ and h. Moreover, if the matrices $g\left(x_{1}, x_{2}, p\right)$ and $\hat{\mathrm{g}}\left(\mathrm{x}_{1}, \hat{\mathrm{x}}_{2}, \hat{\mathrm{p}}\right)$ are nonsingular for all $\mathrm{x}, \hat{\mathrm{x}}, \mathrm{p}, \hat{\mathrm{p}}$, then the system may be feedback linearizable. Consider the observer sliding surface $\mathrm{S}_{\mathrm{o}}=\hat{\mathrm{x}}_{1}-\mathrm{x}_{1}=0_{\mathrm{n}}$, the observer can be written as:

$$
\begin{aligned}
& \dot{\hat{x}}_{1}=-\Gamma_{1}\left(\hat{x}_{1}-x_{1}\right)+\Theta_{1}(t) \tanh \left(\mathrm{k}_{\mathrm{o}} \mathrm{S}_{\mathrm{o}}\right)+\hat{\mathrm{x}}_{2}, \\
& \dot{\hat{\mathrm{x}}}_{2}=-\Gamma_{2}\left(\hat{\mathrm{x}}_{1}-\mathrm{x}_{1}\right)+\Theta_{2}(\mathrm{t}) \tanh \left(\mathrm{k}_{\mathrm{o}} \mathrm{S}_{\mathrm{o}}\right) \\
& +\hat{\mathrm{h}}\left(\mathrm{x}_{1}, \hat{\mathrm{p}}\right)^{-1}\left[\hat{\mathrm{f}}\left(\mathrm{x}_{1}, \hat{\mathrm{x}}_{2}, \hat{\mathrm{p}}\right)+\hat{\mathrm{g}}\left(\mathrm{x}_{1}, \hat{\mathrm{x}}_{2}, \hat{\mathrm{p}}\right) \mathrm{u}\left(\mathrm{x}_{1}, \hat{\mathrm{x}}_{2}, \hat{\mathrm{p}}\right)\right],
\end{aligned}
$$

where $\Gamma_{1}=\operatorname{diag}\left[\gamma_{11} \cdots \gamma_{1 \mathrm{n}}\right], \quad \Gamma_{2}=\operatorname{diag}\left[\gamma_{21} \cdots \gamma_{2 \mathrm{n}}\right]$ with $\gamma_{i j}>0, i=1,2$ and $j=1, n . k_{o}>0$ is a design parameter. $\Theta_{1}=\operatorname{diag}\left[\theta_{11} \cdots \theta_{1 \mathrm{n}}\right]$ and $\Theta_{2}=\operatorname{diag}\left[\theta_{21} \cdots \theta_{21}\right]$ are time-varying gains defined by $(\lambda$-modification is included $)$ :

$\left.\dot{\Theta}_{1}(\mathrm{t})=-\lambda_{1} \Theta_{1}(\mathrm{t})-\rho_{1} \operatorname{diag}|| \hat{\mathrm{x}}_{11}-\mathrm{x}_{11}|\cdots| \hat{\mathrm{x}}_{1 \mathrm{n}}-\mathrm{x}_{1 \mathrm{n}} \mid\right]$,

$\dot{\Theta}_{2}(\mathrm{t})=-\lambda_{2} \Theta_{2}(\mathrm{t})-\rho_{2} \operatorname{diag}\left[\left|\hat{\mathrm{x}}_{11}-\mathrm{x}_{11}\right| \cdots\left|\hat{\mathrm{x}}_{1 \mathrm{n}}-\mathrm{x}_{1 \mathrm{n}}\right|\right]$,

where $\lambda_{1}=\operatorname{diag}\left[\lambda_{11} \cdots \lambda_{1 n}\right], \lambda_{2}=\operatorname{diag}\left[\lambda_{21} \cdots \lambda_{2 n}\right]$, $\rho_{1}=\operatorname{diag}\left[\rho_{11} \cdots \rho_{1 \mathrm{n}}\right], \quad \rho_{2}=\operatorname{diag}\left[\rho_{21} \cdots \rho_{2 n}\right]$, with $\lambda_{1 i}, \lambda_{2 i}, \rho_{1 i}, \rho_{2 i}, i=1, \cdots, n$ positive constants.
Remark 1: The dynamics (3) and (4) of the switching force the matrices $\Theta_{1}$ and $\Theta_{2}$ to the negative values. They are almost zero when the observer is in the sliding surface neighbourhood. In order to satisfy the attractiveness condition $\dot{\mathrm{S}}_{\mathrm{oi}} \mathrm{S}_{\mathrm{oi}}<0, \quad \mathrm{i}=1, \ldots, \mathrm{n}$, the gain $\Theta_{1}$ must be chosen such that $-\theta_{1 \mathrm{i}}(\mathrm{t})>\left|\hat{\mathrm{x}}_{2 \mathrm{i}}(\mathrm{t})-\mathrm{x}_{2 \mathrm{i}}(\mathrm{t})\right|, \mathrm{i}=1, \ldots, \mathrm{n}, \forall \mathrm{t} \in\left[\begin{array}{ll}0 & \infty\end{array}\right)$.

By an appropriate choice of the matrices $\lambda_{1}$ and $\rho_{1}$, the above condition at $t=0$ remains satisfied for any $\mathrm{t}>0$.

If the active torque delivered by the joint DC-motor is considered as the control input, the model of the $n$-DOF robotic manipulator is

$H\left(q, m_{p}\right) \ddot{q}+C\left(q, \dot{q}, m_{p}\right) \dot{q}+F \dot{q}+G\left(q, m_{p}\right)=u+d$

where $q=\left[\begin{array}{lll}q_{1} & \ldots & q_{n}\end{array}\right]^{T}$ is the vector of link positions, $\mathrm{H}\left(\mathrm{q}, \mathrm{m}_{\mathrm{P}}\right) \in \mathfrak{R}^{\mathrm{nxn}}$ is the positive definite inertia matrix, $C\left(q, \dot{\mathrm{q}}, \mathrm{m}_{\mathrm{p}}\right) \in \mathfrak{R}^{\mathrm{nxn}}$ is the Coriolis and centripetal force matrix, $F \in \mathfrak{R}^{\mathrm{nxn}}$ is a positive semidefinite diagonal matrix with the viscous friction coefficients, $\mathrm{u} \in \mathfrak{R}^{\mathrm{n}}$ is the vector of driving torques. Define the unknown time-varying parameter vector $\mathrm{p}(\mathrm{t})=\left[\mathrm{m}_{\mathrm{p}}(\mathrm{t}), \mathrm{d}^{\mathrm{T}}(\mathrm{t})\right]^{\mathrm{T}} \in \mathfrak{R}^{\mathrm{n}_{\mathrm{p}}}$, where $\mathrm{m}_{\mathrm{p}}(\mathrm{t})$ is the payload and $\mathrm{d}(\mathrm{t})$ is an additive input disturbance. Let $\mathrm{q}=\mathrm{x}_{1}=\left[\begin{array}{lll}\mathrm{x}_{11} \ldots & \mathrm{x}_{1 \mathrm{n}}\end{array}\right]^{\mathrm{T}}, \quad \dot{\mathrm{q}}=\mathrm{x}_{2}=\left[\begin{array}{lll}\mathrm{x}_{21} \ldots & \mathrm{x}_{2 \mathrm{n}}\end{array}\right]^{\mathrm{T}}$ be the angular positions and velocity vectors, respectively. The measurements only concern the link positions $y=x_{1}$. The robot state space representation can be written as

$\dot{\mathrm{x}}_{1}=\mathrm{x}_{2}$

$\dot{x}_{2}=-H\left(x_{1}, m_{p}\right)^{-1}\left[\begin{array}{l}C\left(x_{1}, x_{2}, m_{p}\right) x_{2} \\ +G\left(x_{1}, m_{P}\right)+F x_{2}-u-d\end{array}\right]$.

Taking into account the uncertainties, one can define:

$$
\begin{aligned}
& \hat{\mathrm{H}}\left(\mathrm{x}_{1}, \hat{\mathrm{m}}_{\mathrm{p}}\right)=\hat{\mathrm{H}}_{1}\left(\mathrm{x}_{1}\right)+\hat{\mathrm{H}}_{2}\left(\mathrm{x}_{1}\right) \hat{\mathrm{m}}_{\mathrm{p}}, \\
& \hat{\mathrm{C}}\left(\mathrm{x}_{1}, \hat{\mathrm{x}}_{2}, \hat{\mathrm{m}}_{\mathrm{p}}\right)=\hat{\mathrm{C}}_{1}\left(\mathrm{x}_{1}, \hat{\mathrm{x}}_{2}\right)+\hat{\mathrm{C}}_{2}\left(\mathrm{x}_{1}, \hat{\mathrm{x}}_{2}\right) \hat{\mathrm{m}}_{\mathrm{P}}, \\
& \hat{\mathrm{G}}\left(\mathrm{x}_{1}, \hat{\mathrm{m}}_{\mathrm{p}}\right)=\hat{\mathrm{G}}_{1}\left(\mathrm{x}_{1}\right)+\hat{\mathrm{G}}_{2}\left(\mathrm{x}_{1}\right) \hat{\mathrm{m}}_{\mathrm{p}},
\end{aligned}
$$

as the estimates of the function matrices: $\mathrm{H}\left(\mathrm{x}_{1}, \mathrm{~m}_{\mathrm{p}}\right), \mathrm{C}\left(\mathrm{x}_{1}, \mathrm{x}_{2}, \mathrm{~m}_{\mathrm{p}}\right), \mathrm{G}\left(\mathrm{x}_{1}, \mathrm{~m}_{\mathrm{p}}\right)$. Without loss of the generality, the friction is considered as an uncertain positive constant diagonal matrix $\hat{F}$.

The following assumptions have to be done:

A1: The reference signals $y_{r i}(t) i=1, \cdots, n$ are $C^{n}$ functions;

A2: $\hat{\mathrm{H}}\left(\mathrm{x}_{1}, \hat{\mathrm{m}}_{\mathrm{p}}\right)$ and $\mathrm{H}\left(\mathrm{x}_{1}, \mathrm{~m}_{\mathrm{p}}\right)$ are non-singular matrices for all $\mathrm{x}_{1}, \mathrm{~m}_{\mathrm{p}}, \hat{\mathrm{m}}_{\mathrm{p}}$;

A3: The time-varying vector $\mathrm{p}(\mathrm{t})$ is bounded for all $\mathrm{t}$. 
With the previous notations, the model (6) can be rewritten as:

$$
\begin{aligned}
& {\left[\begin{array}{cc}
\mathrm{I}_{\mathrm{n}} & 0 \\
0 & \mathrm{H}
\end{array}\right]\left[\begin{array}{l}
\dot{\mathrm{x}}_{1} \\
\dot{\mathrm{x}}_{2}
\end{array}\right]=-\left[\begin{array}{ll}
0 & \mathrm{I}_{\mathrm{n}} \\
0 & \mathrm{C}
\end{array}\right]\left[\begin{array}{l}
\mathrm{x}_{1} \\
\mathrm{x}_{2}
\end{array}\right]} \\
& -\left[\begin{array}{cc}
0 & 0 \\
0 & \mathrm{~F}
\end{array}\right]\left[\begin{array}{l}
\mathrm{x}_{1} \\
\mathrm{x}_{2}
\end{array}\right]-\left[\begin{array}{c}
0 \\
\mathrm{G}
\end{array}\right]+\left[\begin{array}{c}
0 \\
\mathrm{u}+\mathrm{d}
\end{array}\right] .
\end{aligned}
$$

The smooth sliding observer with switching function $\mathrm{k}$-tanh and adaptively updated gains (including $\lambda$ modification as in (3)-(4)), is given by the equations:

$$
\begin{aligned}
& \dot{\hat{\mathrm{x}}}_{1}=-\Gamma_{1}\left(\hat{\mathrm{x}}_{1}-\mathrm{x}_{1}\right)+\Theta_{1}(\mathrm{t}) \tanh \left(\mathrm{k}_{\mathrm{o}} \mathrm{S}_{\mathrm{o}}\right)+\hat{\mathrm{x}}_{2} \\
& \dot{\hat{\mathrm{x}}}_{2}=-\Gamma_{2}\left(\hat{\mathrm{x}}_{1}-\mathrm{x}_{1}\right)+\Theta_{2}(\mathrm{t}) \tanh \left(\mathrm{k}_{\mathrm{o}} \mathrm{S}_{\mathrm{o}}\right) \\
& -\hat{\mathrm{H}}^{-1}\left[\hat{\mathrm{C}} \hat{\mathrm{x}}_{2}+\hat{\mathrm{F}} \hat{\mathrm{x}}_{2}+\hat{\mathrm{G}}-\hat{\mathrm{u}}\right] .
\end{aligned}
$$

The estimate error equation can be written as

$\dot{\widetilde{\mathrm{x}}}_{2}=-\Theta_{2} \Theta_{1}^{-1} \widetilde{\mathrm{x}}_{2}-\hat{\mathrm{H}}^{-1}\left[\hat{\mathrm{C}} \hat{\mathrm{x}}_{2}+\hat{\mathrm{F}} \hat{\mathrm{x}}_{2}+\hat{\mathrm{G}}-\hat{\mathrm{u}}\right]$

$+\mathrm{H}^{-1}\left[\mathrm{Cx}_{2}+\mathrm{Fx}_{2}+\mathrm{G}-\mathrm{u}-\mathrm{d}\right]$

Above equation assures the stability of the observer and exponential convergence rate The smooth switching function allows considering that $\mathrm{S}_{\mathrm{o}} \approx 0, \quad \dot{\mathrm{S}}_{\mathrm{O}} \approx 0 \quad$ are approximate conditions satisfied during sliding.

\section{ADAPTIVE GAIN SMOOTH SLIDING CONTROLLER}

The controller is developed, assuming that $\mathrm{x}_{1}$ is known and $\mathrm{x}_{2}$ is given by the observer. Corresponding to the $\mathrm{n}$-dimensional control input, the controller sliding surface is defined as:

$$
\hat{\mathrm{S}}_{\mathrm{c}}\left(\mathrm{x}_{1}, \hat{\mathrm{x}}_{2}\right)=\hat{\mathrm{x}}_{2}(\mathrm{t})-\dot{\mathrm{y}}_{\mathrm{r}}(\mathrm{t})+\psi\left(\mathrm{x}_{1}(\mathrm{t})-\mathrm{y}_{\mathrm{r}}(\mathrm{t})\right),
$$

where $y_{r}(t)$ represents the trajectory to be tracked. The matrix $\psi=\operatorname{diag}\left[\psi_{1} \ldots \psi_{\mathrm{n}}\right]$, with constants $\psi_{i} \succ 0, i=1, \cdots, n$, determines the dynamics during sliding. The sliding surface is attractive if the following condition holds:

$\dot{\hat{\mathrm{S}}}_{\mathrm{ci}} \hat{\mathrm{S}}_{\mathrm{ci}}<0, \quad \mathrm{i}=1, \ldots, \mathrm{n}$.

The time derivative of the sliding surface can be written as:

$$
\begin{aligned}
& \dot{\hat{\mathrm{S}}}_{\mathrm{c}}=\dot{\hat{\mathrm{x}}}_{2}-\ddot{\mathrm{y}}_{1 \mathrm{r}}+\psi\left(\hat{\mathrm{x}}_{2}-\dot{\mathrm{y}}_{1 \mathrm{r}}\right)=\hat{\mathrm{h}}\left(\mathrm{x}_{1}, \hat{\mathrm{m}}_{\mathrm{p}}\right)^{-1} \\
& {\left[\hat{\mathrm{f}}\left(\mathrm{x}_{1}, \hat{\mathrm{x}}_{2}, \hat{\mathrm{p}}\right)+\hat{\mathrm{g}}\left(\mathrm{x}_{1}, \hat{\mathrm{x}}_{2}, \hat{\mathrm{p}}\right) \hat{\mathrm{u}}\left(\mathrm{x}_{1}, \hat{\mathrm{x}}_{2}, \hat{\mathrm{p}}\right)\right]-\ddot{\mathrm{y}}_{\mathrm{r}}+\psi\left(\hat{\mathrm{x}}_{2}-\dot{\mathrm{y}}_{\mathrm{r}}\right)}
\end{aligned}
$$

If $k$-tanh is used as the switching function and if the matrix $\eta=\operatorname{diag}\left[\eta_{1} \cdots \eta_{n}\right]$ is time-varying (including the $\lambda$-modification), with

$$
\dot{\eta}(\mathrm{t})=-\lambda_{\mathrm{c}} \eta(\mathrm{t})-\rho_{\mathrm{c}} \operatorname{diag}\left[\left|\hat{\mathrm{S}}_{\mathrm{cl}}\right| \quad \ldots\left|\hat{\mathrm{S}}_{\mathrm{cn}}\right|\right],
$$

then the controller fulfilling the sliding condition $\dot{\hat{\mathrm{S}}}_{\mathrm{c}}=0$ can be expressed as:

$$
\begin{aligned}
& \hat{\mathrm{u}}=-\hat{\mathrm{f}}\left(\mathrm{x}_{1}, \hat{\mathrm{x}}_{2}, \hat{\mathrm{p}}\right)+\hat{\mathrm{g}}^{-1}\left(\mathrm{x}_{1}, \hat{\mathrm{x}}_{2}, \hat{\mathrm{p}}\right) \hat{\mathrm{h}}\left(\mathrm{x}_{1}, \hat{\mathrm{p}}\right) \\
& {\left[-\psi \hat{\mathrm{S}}_{\mathrm{c}}+\eta(\mathrm{t}) \tanh \left(\mathrm{k}_{\mathrm{c}} \hat{\mathrm{S}}_{\mathrm{c}}\right)+\ddot{y}_{\mathrm{r}}-\psi\left(\hat{\mathrm{x}}_{2}-\dot{\mathrm{y}}_{\mathrm{r}}\right)\right]}
\end{aligned}
$$

where $\lambda_{\mathrm{c}}=\operatorname{diag}\left[\lambda_{\mathrm{cl}} \cdots \lambda_{\mathrm{cn}}\right], \quad \rho_{\mathrm{c}}=\operatorname{diag}\left[\rho_{\mathrm{cl}} \cdots \rho_{\mathrm{cn}}\right]$ are positive definite matrices. The term $-\psi \hat{\mathrm{S}}_{\mathrm{c}}$ is introduced to reduce the controller to a classical feedback linearization one (Marino and Tomei 1995) if the switching term is set to zero.

To fulfil the attractiveness condition (13), it is necessary to express the derivative of the sliding surface (12):

$$
\begin{aligned}
& \dot{\hat{\mathrm{S}}}_{\mathrm{c}}=\dot{\hat{\mathrm{x}}}_{2}-\ddot{\mathrm{y}}_{\mathrm{r}}+\psi\left(\hat{\mathrm{x}}_{2}-\dot{\mathrm{y}}_{\mathrm{r}}\right)=-\hat{\mathrm{H}}\left(\mathrm{x}_{1}, \hat{\mathrm{m}}_{\mathrm{p}}\right)^{-1} \\
& {\left[\hat{\mathrm{C}}\left(\mathrm{x}_{1}, \hat{\mathrm{x}}_{2}, \hat{\mathrm{m}}_{\mathrm{p}}\right) \hat{\mathrm{x}}_{2}+\mathrm{F} \hat{\mathrm{x}}_{2}+\hat{\mathrm{G}}\left(\mathrm{x}_{1}, \hat{\mathrm{m}}_{\mathrm{p}}\right)-\hat{\mathrm{u}}\right] .} \\
& -\ddot{\mathrm{y}}_{\mathrm{r}}+\psi\left(\hat{\mathrm{x}}_{2}-\dot{\mathrm{y}}_{\mathrm{r}}\right)
\end{aligned}
$$

Similarly as for the observer, using the switching function $k$-tanh and the $\lambda$-modification in the gain, the sliding condition is fulfilled if the control input is chosen as:

$$
\begin{aligned}
& \hat{\mathrm{u}}=\hat{\mathrm{C}}\left(\mathrm{x}_{1}, \hat{\mathrm{x}}_{2}, \hat{\mathrm{m}}_{\mathrm{p}}\right) \hat{\mathrm{x}}_{2}+\hat{\mathrm{F}} \hat{\mathrm{x}}_{2}+\hat{\mathrm{G}}\left(\mathrm{x}_{1}, \hat{\mathrm{m}}_{\mathrm{p}}\right) \\
& +\hat{\mathrm{H}}\left(\mathrm{x}_{1}, \hat{\mathrm{m}}_{\mathrm{p}}\right)\left[\begin{array}{l}
-\psi \hat{\mathrm{S}}_{\mathrm{c}}+\eta(\mathrm{t}) \tanh \left(\mathrm{k}_{\mathrm{c}} \hat{\mathrm{S}}_{\mathrm{c}}\right) \\
+\ddot{\mathrm{y}}_{\mathrm{r}}-\psi\left(\hat{\mathrm{x}}_{2}-\dot{\mathrm{y}}_{\mathrm{r}}\right)
\end{array}\right] .
\end{aligned}
$$

The controller switching gain $\eta(t)$ is adaptively updated as in (15).

Remark 1. The observation error is nonzero if a $\mathrm{k}$ tanh function is used as a switching function in the observer equations. The controller sliding surface $\hat{\mathrm{S}}_{\mathrm{c}}$ can still be attractive by choosing sufficiently large initial values for the switching gains $\Theta_{1}$ and $\Theta_{2}$. Moreover, the tracking error does not go to zero on the controller sliding surface because the smooth controller is used ( $\mathrm{k}$-tanh switching function).

Remark 2. In order to reduce the influence of the velocity estimation error in the control input, the relative weight of the states $\hat{x}_{2}$ in the definition of the sliding surface should be decreased. This explains the introduction of the supplementary term $-\psi \hat{S}_{c}$ in the control input. The increase of the parameter $\psi$ is limited by the switching frequency and possible measurement noise.

Remark 3. The initial value of the switching controller gain must be defined to guarantee the sliding condition after convergence of the observer, when the error in state estimates is bounded.

Remark 4. The observer and the controller, both in a smoothed form, can achieve high performance. By choosing the value of the constant $\mathrm{k}_{\mathrm{o}}>\mathrm{k}_{\mathrm{c}}$, the smooth switching function of the observer is closer to a pure relay than the smooth switching function of the controller. Therefore, the observer converges faster than the controller with a small estimate error. The state estimates could be chattering-free, independently of the values of the gains $\Theta_{1}$ and $\Theta_{2}$. 
Furthermore, by choosing the matrices $\Theta_{1}$ and $\Theta_{2}$ adaptively updated as in (3) - (4), the magnitudes of the switching function go to small values while the link position errors go to small values.

\section{PARAMETER IDENTIFICATION BASED ON SMOOTH SLIDING OBSERVER-CONTROLLER}

The way followed for the time-varying parameter identification is quite different from that proposed by $\mathrm{Xu}$, Pan and Lee (2003). Firstly, it is based on the state estimates and on the faster convergence of the observer than the controller. Secondly, it is based on a smooth sliding observer-controller (both of them having adaptive switching gain). A zero or small state estimate error leads to zero or small tracking error and small gains of the corresponding switching function. Then during sliding, the weight of the switching term is negligible w.r.t. the compensation part. Define the parameter vector estimate as $\hat{\mathrm{p}}$. If the functions $\mathrm{f}, \mathrm{g}$ and $\mathrm{h}$ are linear in time-varying parameters, each term of the system (1) can be expressed as follows:

$$
\begin{aligned}
& {\left[\begin{array}{cc}
\mathrm{I}_{\mathrm{n}} & 0_{\mathrm{nxn}} \\
0_{\mathrm{nxn}} & \hat{\mathrm{h}}\left(\mathrm{x}_{1}, \hat{\mathrm{p}}\right)
\end{array}\right]\left[\begin{array}{c}
\dot{\mathrm{x}}_{1} \\
\dot{\hat{\mathrm{x}}}_{2}
\end{array}\right]=\left[\begin{array}{c}
\dot{\mathrm{x}}_{1} \\
\hat{\mathrm{h}}_{1}\left(\mathrm{x}_{1}\right) \dot{\hat{\mathrm{x}}}_{2}
\end{array}\right]} \\
& +\left[\begin{array}{cc}
0_{\mathrm{n}} & 0_{\mathrm{nx}}\left(\mathrm{n}_{\mathrm{p}}-1\right) \\
\hat{\mathrm{h}}_{2}\left(\mathrm{x}_{1}\right) \dot{\hat{\mathrm{x}}}_{2} & \varphi_{\mathrm{nx}}^{1}\left(\mathrm{n}_{\mathrm{p}}-1\right)
\end{array}\right] \hat{\mathrm{p}}(\mathrm{t}) \\
& {\left[\begin{array}{c}
\hat{x}_{2} \\
\hat{f}\left(x_{1}, \hat{x}_{2}, \hat{p}\right)
\end{array}\right]=\left[\begin{array}{c}
\hat{x}_{2} \\
\hat{f}_{1}\left(x_{1}, \hat{x}_{2}\right)
\end{array}\right]} \\
& +\left[\begin{array}{cc}
0_{n} & 0_{n x}\left(n_{p}-1\right) \\
\hat{f}_{2}\left(x_{1}, \hat{x}_{2}\right) & \varphi_{n x}^{2}\left(n_{p}-1\right)
\end{array}\right] \hat{p}(t) \\
& {\left[\begin{array}{cc}
\mathrm{I}_{\mathrm{n}} & 0_{\mathrm{nxn}} \\
0_{\mathrm{nxn}} & \hat{\mathrm{g}}\left(\mathrm{x}_{1}, \hat{\mathrm{x}}_{2}, \hat{\mathrm{p}}\right)
\end{array}\right]\left[\begin{array}{c}
0_{\mathrm{n}} \\
\hat{\mathrm{u}}
\end{array}\right]=\left[\begin{array}{c}
0_{\mathrm{n}} \\
\hat{\mathrm{g}}_{1}\left(\mathrm{x}_{1}, \hat{\mathrm{x}}_{2}, \mathrm{u}\right)
\end{array}\right]} \\
& +\Phi_{3}\left(\mathrm{x}_{1}, \hat{\mathrm{x}}_{2}, \hat{\mathrm{u}}\right) \hat{\mathrm{p}}(\mathrm{t})
\end{aligned}
$$

Define the followings matrices and vectors:

$$
\begin{aligned}
& \hat{\mathrm{H}}_{0}\left(\mathrm{x}_{1}, \hat{\mathrm{p}}\right)=\left[\begin{array}{cc}
\mathrm{I}_{\mathrm{n}} & 0_{\mathrm{nxn}} \\
0_{\mathrm{nxn}} & \hat{\mathrm{h}}\left(\mathrm{x}_{1}, \hat{\mathrm{p}}\right)
\end{array}\right] \text {, } \\
& \hat{\mathrm{h}}_{0}\left(\dot{\mathrm{x}}_{1}, \dot{\hat{\mathrm{x}}}_{2}, \mathrm{x}_{1}, \hat{\mathrm{x}}_{2}\right)=\left[\begin{array}{c}
\dot{\mathrm{x}}_{1} \\
\hat{\mathrm{h}}_{1}\left(\mathrm{x}_{1}\right) \dot{\hat{\mathrm{x}}}_{2}
\end{array}\right] \text {, } \\
& \hat{\Phi}_{1}\left(\dot{\mathrm{x}}_{1}, \dot{\hat{\mathrm{x}}}_{2}, \mathrm{x}_{1}, \hat{\mathrm{x}}_{2}\right)=\left[\begin{array}{cc}
0_{\mathrm{n}} & 0_{\mathrm{nx}}\left(\mathrm{n}_{\mathrm{p}}-1\right) \\
\hat{\mathrm{h}}_{2}\left(\mathrm{x}_{1}\right) \dot{\hat{\mathrm{x}}}_{2} & \varphi_{\mathrm{nx}}^{1}\left(\mathrm{n}_{\mathrm{p}}-1\right)
\end{array}\right] \text {, } \\
& \hat{\mathrm{f}}_{0}\left(\mathrm{x}_{1}, \hat{\mathrm{x}}_{2}, \hat{\mathrm{p}}\right)=\left[\begin{array}{c}
\hat{\mathrm{x}}_{2} \\
\hat{\mathrm{f}}\left(\mathrm{x}_{1}, \hat{\mathrm{x}}_{2}, \hat{\mathrm{p}}\right)
\end{array}\right], \hat{\mathrm{f}}_{01}\left(\mathrm{x}_{1}, \hat{\mathrm{x}}_{2}\right)=\left[\begin{array}{c}
\hat{\mathrm{x}}_{2} \\
\hat{\mathrm{f}}_{1}\left(\mathrm{x}_{1}, \hat{\mathrm{x}}_{2}\right)
\end{array}\right] \text {, } \\
& \hat{\Phi}_{2}\left(\mathrm{x}_{1}, \hat{\mathrm{x}}_{2}\right)=\left[\begin{array}{cc}
0_{\mathrm{n}} & 0_{\mathrm{nx}}\left(\mathrm{n}_{\mathrm{p}}-1\right) \\
\hat{\mathrm{f}}_{2}\left(\mathrm{x}_{1}, \hat{\mathrm{x}}_{2}\right) & \varphi_{\mathrm{nx}}^{2}\left(\mathrm{n}_{\mathrm{p}}-1\right)
\end{array}\right] \text {, } \\
& \hat{\mathrm{G}}_{0}\left(\mathrm{x}_{1}, \hat{\mathrm{x}}_{2}, \hat{\mathrm{p}}\right)=\left[\begin{array}{cc}
\mathrm{I}_{\mathrm{n}} & 0_{\mathrm{nxn}} \\
0_{\mathrm{nxn}} & \hat{\mathrm{g}}\left(\mathrm{x}_{1}, \hat{\mathrm{x}}_{2}, \hat{\mathrm{p}}\right)
\end{array}\right],
\end{aligned}
$$

In the relationships (22) - (28), $\hat{\mathrm{H}}_{0}, \hat{\mathrm{G}}_{0}$ are $2 n \times 2 n$ matrices, $\hat{\Phi}_{1}, \hat{\Phi}_{2}, \hat{\Phi}_{3}$ are $2 n x n_{p}$ matrices and $\hat{\mathrm{f}}_{0}, \hat{\mathrm{f}}_{01}, \hat{\mathrm{g}}_{0}, \hat{\mathrm{h}}_{0}$ are $2 \mathrm{n}$ vectors. With the previous notations the robot model can be expressed as:

$\hat{\mathrm{H}}_{0}\left(\mathrm{x}_{1}, \hat{\mathrm{p}}\right) \dot{\mathrm{x}}=\hat{\mathrm{f}}_{0}\left(\mathrm{x}_{1}, \hat{\mathrm{x}}_{2}\right)+\hat{\mathrm{G}}_{0}\left(\mathrm{x}_{1}, \hat{\mathrm{x}}_{2}, \hat{\mathrm{p}}\right) \hat{\mathrm{u}}_{0}$,

where $\hat{\mathrm{u}}_{0}=\left[\begin{array}{ll}0 \mathrm{~T} & \hat{\mathrm{u}}^{\mathrm{T}}\end{array}\right]^{\mathrm{T}}$.

Assumption 4: For each element $p_{i}(t), i=1 \ldots n_{p}$ of the unknown parameter vector $\mathrm{p}(\mathrm{t})$, there exist a priori known values $\mathrm{p}_{\mathrm{i}_{\min }}, \mathrm{p}_{\mathrm{i}_{\max }}$, such that $\mathrm{p}_{\mathrm{i}_{\min }} \leq \mathrm{p}_{\mathrm{i}} \leq \mathrm{p}_{\mathrm{i}_{\max }}$.

Define the matrix

$\hat{\Phi}\left(\dot{\mathrm{x}}_{1}, \dot{\hat{\mathrm{x}}}_{2}, \mathrm{x}_{1}, \hat{\mathrm{x}}_{2}, \mathrm{u}\right)=-\hat{\Phi}_{1}+\hat{\Phi}_{2}+\hat{\Phi}_{3}$

and the vector

$\hat{\omega}\left(\dot{\mathrm{x}}_{1}, \dot{\hat{\mathrm{x}}}_{2}, \mathrm{x}_{1}, \hat{\mathrm{x}}_{2}, \mathrm{u}\right)=\hat{\mathrm{h}}_{0}-\hat{\mathrm{f}}_{0}-\hat{\mathrm{g}}_{0}$

of $2 \mathrm{nxn}_{\mathrm{p}}$ and $2 \mathrm{n}$-dimensions respectively. Suppose that $\hat{\Phi}^{\mathrm{T}} \hat{\Phi}$ is a nonsingular matrix, then the parameter estimate $\hat{\mathrm{p}}$ can be computed as the minimum residuum solution of the system $\hat{\Phi} \hat{p}=\widehat{\omega}$. In order ensure the boundedness of $\hat{\mathrm{p}}$, the following algorithm is used to compute the parameter estimate:

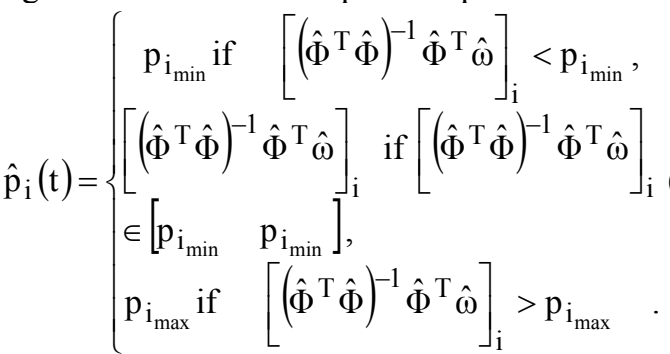

With the observer (2) and the control law (18), (with smooth switching term and gains adaptively updated), the neighborhood of the controller sliding surface (30) can be reached in finite time. Choosing the Lyapunov function $\mathrm{V}=\hat{\mathrm{S}}_{\mathrm{c}}^{\mathrm{T}} \hat{\mathrm{S}}_{\mathrm{c}} / 2$ and defining the set $\left\{\left\|\hat{\mathrm{S}}_{\mathrm{c}}\right\| \leq \frac{1}{\mathrm{k}_{\mathrm{c}}}\right\}$, it can be proven that there exists some $T \geq 0$ such that $\forall t \in[0, T),\left\|\hat{\mathrm{S}}_{\mathrm{c}}(\mathrm{t})\right\|>\frac{1}{\mathrm{k}_{\mathrm{c}}}$ and $\left\|\hat{S}_{c}(t)\right\|$ is strictly decreasing until it reaches the set in finite time and remains inside thereafter (for $\mathrm{t} \geq \mathrm{T}$ ).

Particularizing the previous relationships for an ndegree of freedom robot manipulator, considering the estimates of the velocities and the uncertainties in the parameters, the robot model (10) becomes:

$$
\begin{aligned}
& {\left[\begin{array}{c}
\dot{\mathrm{x}}_{1} \\
\hat{\mathrm{H}}_{1} \dot{\hat{\mathrm{x}}}_{2}
\end{array}\right]+\left[\begin{array}{c}
0_{\mathrm{n}} \\
\hat{\mathrm{H}}_{2}
\end{array}\right] \hat{\mathrm{m}}_{\mathrm{p}}=-\left[\begin{array}{c}
\hat{\mathrm{x}}_{2} \\
\hat{\mathrm{C}}_{1} \hat{\mathrm{x}}_{2}+\hat{\mathrm{F}}_{2}+\hat{\mathrm{G}}_{1}
\end{array}\right]} \\
& -\left[\begin{array}{c}
0_{\mathrm{n}} \\
\hat{\mathrm{C}}_{2} \hat{\mathrm{x}}_{2}+\hat{\mathrm{G}}_{2}
\end{array}\right] \hat{\mathrm{m}}_{\mathrm{p}}+\left[\begin{array}{c}
0_{\mathrm{n}} \\
\hat{\mathrm{u}}
\end{array}\right]+\left[\begin{array}{c}
0_{\mathrm{n}} \\
\mathrm{d}
\end{array}\right]
\end{aligned}
$$

Define the $2 \mathrm{n} \times 2 \mathrm{n}$ matrices and $2 \mathrm{n}$ vectors:

$\hat{\mathrm{H}}_{0}=\left[\begin{array}{cc}\mathrm{I}_{\mathrm{n}} & 0_{\mathrm{nxn}} \\ 0_{\mathrm{nxn}} & \hat{\mathrm{H}}\end{array}\right], \hat{\mathrm{h}}_{0}=\left[\begin{array}{c}\dot{\mathrm{x}}_{1} \\ \hat{\mathrm{H}}_{1} \dot{\hat{\mathrm{x}}}_{2}\end{array}\right]$, 


$$
\begin{aligned}
& \hat{\Phi}_{1}=\left[\begin{array}{cc}
0_{\mathrm{n}} & 0_{\mathrm{nx}}\left(\mathrm{n}_{\mathrm{p}}-1\right) \\
\hat{\mathrm{H}}_{2} \dot{\hat{\mathrm{x}}}_{2} & 0_{\mathrm{nx}}\left(\mathrm{n}_{\mathrm{p}}-1\right)
\end{array}\right], \\
& \hat{\mathrm{f}}_{0}=\left[\begin{array}{c}
\hat{\mathrm{x}}_{2} \\
-\hat{\mathrm{C}} \hat{\mathrm{x}}_{2}-\hat{\mathrm{F}} \hat{\mathrm{x}}_{2}-\hat{\mathrm{G}}
\end{array}\right], \hat{\mathrm{f}}_{01}=\left[\begin{array}{c}
\hat{\mathrm{x}}_{2} \\
-\hat{\mathrm{C}}_{1} \hat{\mathrm{x}}_{2}-\hat{\mathrm{F}}_{2}-\hat{\mathrm{G}}_{1}
\end{array}\right], \\
& \hat{\Phi}_{2}=\left[\begin{array}{cc}
0_{\mathrm{n}} & 0_{\mathrm{nx}}\left(\mathrm{n}_{\mathrm{p}}-1\right) \\
-\hat{\mathrm{C}}_{2} \hat{\mathrm{x}}_{2}-\hat{\mathrm{G}}_{2} & 1_{\mathrm{nx}}\left(\mathrm{n}_{\mathrm{p}}-1\right)
\end{array}\right], \\
& \hat{\mathrm{G}}_{0}=\left[\begin{array}{cc}
\mathrm{I}_{\mathrm{n}} & 0_{\mathrm{nxn}} \\
0_{\mathrm{nxn}} & \mathrm{I}_{\mathrm{n}}
\end{array}\right], \hat{\mathrm{g}}_{0}\left(\mathrm{x}_{1}, \hat{\mathrm{x}}_{2}, \hat{\mathrm{u}}\right)=\left[\begin{array}{c}
0_{\mathrm{n}} \\
\hat{\mathrm{u}}
\end{array}\right], \\
& \hat{\Phi}_{3}=\left[\begin{array}{cc}
0_{\mathrm{nxn}} & 0_{\mathrm{nx}}\left(\mathrm{n}_{\mathrm{p}}-1\right) \\
0_{\mathrm{n}} & 0_{\mathrm{nx}}\left(\mathrm{n}_{\mathrm{p}}-1\right)
\end{array}\right] .
\end{aligned}
$$

This allows writing

$\hat{\mathrm{H}}_{0}\left[\begin{array}{c}\dot{\mathrm{x}}_{1} \\ \hat{\mathrm{x}}_{2}\end{array}\right]=\hat{\mathrm{f}}_{0}+\hat{\mathrm{G}}_{0} \hat{\mathrm{u}}$

with equivalent form

$\hat{\mathrm{h}}_{0}+\hat{\Phi}_{1} \hat{\mathrm{p}}=\hat{\mathrm{f}}_{01}+\hat{\Phi}_{2} \hat{\mathrm{p}}+\hat{\mathrm{g}}_{0}+\hat{\Phi}_{3} \hat{\mathrm{p}}$.

Remark 5: The smooth sliding controller allows the using of the compensation part as equivalent control input signal during sliding. The adaptive gain of the controller switching term goes to zero or becomes very small, depending on the error in the state estimate.

\section{CLOSED LOOP SIMULATION}

A 2-degree of freedom vertical robot with 2 rigid revolute joints, 2 rigid links, a time varying payload $\mathrm{m}_{\mathrm{p}}(\mathrm{t})$ and an additive disturbance $\mathrm{d}(\mathrm{t})$ on the control input has been considered to test the smooth variable structure observer-controller with the time-varying parameter identification scheme developed in this paper. The position and velocities vectors are: $\mathrm{x}_{1}=\left[\begin{array}{ll}\mathrm{x}_{11} & \mathrm{x}_{12}\end{array}\right]^{\mathrm{T}}$ and $\mathrm{x}_{2}=\left[\begin{array}{ll}\mathrm{x}_{21} & \mathrm{x}_{22}\end{array}\right]^{\mathrm{T}}$.

The trajectory to be tracked is defined as $\mathrm{y}_{\mathrm{r}}=\left[\begin{array}{ll}-0.5+0.3 \sin (\mathrm{t}-0.3) & 0.7 \sin (2 \mathrm{t}+0.3)\end{array}\right]^{\mathrm{T}}$.

$\mathbf{p}(t)=\left[3+e^{-0.5 t}-1+0.7 \sin (3 t)\right]^{T}$ is the parameter vector to be identified, $\mathrm{m}_{\mathrm{p}}(\mathrm{t})=3+\mathrm{e}^{-0.5 \mathrm{t}}$ the payload and $d(t)=-1+0.7 \sin (3 t)$ the additive disturbance. The corresponding robot model matrices and vectors are:

$$
\begin{aligned}
& \mathrm{H}\left(\mathrm{x}_{1}, \mathrm{~m}_{\mathrm{p}}\right) \\
& =\left[\begin{array}{cc}
9.77+2.02 \cos \left(\mathrm{x}_{12}\right) & 1.26+1.01 \cos \left(\mathrm{x}_{12}\right) \\
1.26+1.01 \cos \left(\mathrm{x}_{12}\right) & 1.12
\end{array}\right], \\
& +\left[\begin{array}{cc}
2+2 \cos \left(\mathrm{x}_{12}\right) & 1+\cos \left(\mathrm{x}_{12}\right) \\
1+\cos \left(\mathrm{x}_{12}\right) & 1
\end{array}\right] \mathrm{m}_{\mathrm{p}} \\
& \mathrm{C}\left(\mathrm{x}_{1}, \mathrm{x}_{2}, \mathrm{~m}_{\mathrm{p}}\right) \\
& =\sin \left(x_{12}\right)\left\{\begin{array}{l}
{\left[\begin{array}{cc}
-x_{22} & -x_{21}-x_{22} \\
x_{21} & 0
\end{array}\right] 1.01} \\
+\left[\begin{array}{cc}
-x_{22} & -x_{21}-x_{22} \\
x_{21} & 0
\end{array}\right] m_{P}
\end{array}\right\},
\end{aligned}
$$

$\mathrm{G}\left(\mathrm{x}_{1}, \mathrm{~m}_{\mathrm{p}}\right)=\mathrm{g}\left[\begin{array}{c}8.1 \sin \left(\mathrm{x}_{11}\right)+1.13 \sin \left(\mathrm{x}_{11}+\mathrm{x}_{12}\right) \\ 1.13 \sin \left(\mathrm{x}_{11}+\mathrm{x}_{12}\right)\end{array}\right]$
$+\mathrm{g}\left[\begin{array}{c}\sin \left(\mathrm{x}_{11}\right)+\sin \left(\mathrm{x}_{11}+\mathrm{x}_{12}\right) \\ \sin \left(\mathrm{x}_{11}+\mathrm{x}_{12}\right)\end{array}\right] \mathrm{m}_{\mathrm{p}}$

$\mathrm{F}=\operatorname{diag}[10 \quad 10]$,

$\mathrm{h}_{0}=\left[\begin{array}{c}\dot{\mathrm{x}}_{11} \\ \dot{\mathrm{x}}_{12} \\ {\left[9.77+2.02 \cos \left(\mathrm{x}_{12}\right)\right] \dot{\mathrm{x}}_{21}} \\ +\left[1.26+1.01 \cos \left(\mathrm{x}_{12}\right)\right] \dot{\mathrm{x}}_{22} \\ {\left[1.26+1.01 \cos \left(\mathrm{x}_{12}\right)\right] \dot{\mathrm{x}}_{21}+1.12 \dot{\mathrm{x}}_{22}}\end{array}\right]$,

$\Phi_{1}=\left[\begin{array}{cc}0 & 0 \\ 0 & 0 \\ {\left[2+2 \cos \left(\mathrm{x}_{12}\right)\right] \dot{\mathrm{x}}_{21}+\left[1+\cos \left(\mathrm{x}_{12}\right)\right] \dot{\mathrm{x}}_{22}} & 0 \\ {\left[1+\cos \left(\mathrm{x}_{12}\right)\right] \dot{\mathrm{x}}_{21}+\dot{\mathrm{x}}_{22}} & 0\end{array}\right]$

$\mathrm{f}_{01}=\left[\begin{array}{c}\mathrm{x}_{21} \\ \mathrm{x}_{22} \\ 1.01 \sin \left(\mathrm{x}_{12}\right) \mathrm{x}_{22} \mathrm{x}_{21} \\ +\left(\mathrm{x}_{21}+\mathrm{x}_{22}\right) 1.01 \sin \left(\mathrm{x}_{12}\right) \mathrm{x}_{22} \\ -8.1 \mathrm{~g} \sin \left(\mathrm{x}_{11}\right)-1.13 \mathrm{~g} \sin \left(\mathrm{x}_{21}+\mathrm{x}_{22}\right) \\ -10 \mathrm{x}_{21} \\ -1.01 \sin \left(\mathrm{x}_{12}\right) \mathrm{x}_{21}^{2} \\ -1.13 \mathrm{~g} \sin \left(\mathrm{x}_{21}+\mathrm{x}_{22}\right)-10 \mathrm{x}_{22}\end{array}\right]$

$\Phi_{2}=\left[\begin{array}{cc}0 & 0 \\ 0 & 0 \\ \sin \left(\mathrm{x}_{12}\right) \mathrm{x}_{22} \mathrm{x}_{21} & \\ +\left(\mathrm{x}_{21}+\mathrm{x}_{22}\right) \sin \left(\mathrm{x}_{12}\right) \mathrm{x}_{22} & 0 \\ -\mathrm{g} \sin \left(\mathrm{x}_{11}\right)-\mathrm{g} \sin \left(\mathrm{x}_{21}+\mathrm{x}_{22}\right) & \\ -\sin \left(\mathrm{x}_{12}\right) \mathrm{x}_{21}-\mathrm{g} \sin \left(\mathrm{x}_{21}+\mathrm{x}_{22}\right) & 1\end{array}\right]$,

$\hat{\mathrm{g}}_{0}=\left[\begin{array}{llll}0 & 0 & \mathrm{u}_{1} & \mathrm{u}_{2}\end{array}\right]^{\mathrm{T}}, \hat{\Phi}_{3}=\left[0_{4 \times 2}\right]$.

The initial conditions are chosen as:

$\mathrm{x}_{1}(0)=\mathrm{x}_{2}(0)=\hat{\mathrm{x}}_{1}(0)=\left[\begin{array}{ll}0 & 0\end{array}\right]^{\mathrm{T}} ; \hat{\mathbf{x}}_{2}(0)=\left[\begin{array}{ll}-1 & 2\end{array}\right]^{T}$,

$\Theta_{1}(0)=\left[\begin{array}{cc}-10 & 0 \\ 0 & -10\end{array}\right] ; \Theta_{2}(0)=\left[\begin{array}{cc}-100 & 0 \\ 0 & -200\end{array}\right] ;$

$\eta(0)=\left[\begin{array}{cc}-5 & 0 \\ 0 & -10\end{array}\right]$

The following constant design values are chosen: $\lambda_{1}=\lambda_{2}=\lambda_{c}=\operatorname{diag}\left[\begin{array}{ll}1 & 1\end{array}\right], \quad \Gamma_{1}=\operatorname{diag}\left[\begin{array}{ll}10 & 10\end{array}\right]$, $\Gamma_{2}=\operatorname{diag}\left[\begin{array}{ll}5000 & 5000\end{array}\right], \quad \rho_{1}=\rho_{2}=\rho_{\mathrm{c}}=\operatorname{diag}\left[\begin{array}{ll}1 & 1\end{array}\right]$, $\psi=\operatorname{diag}\left[\begin{array}{ll}20 & 20\end{array}\right]$. 

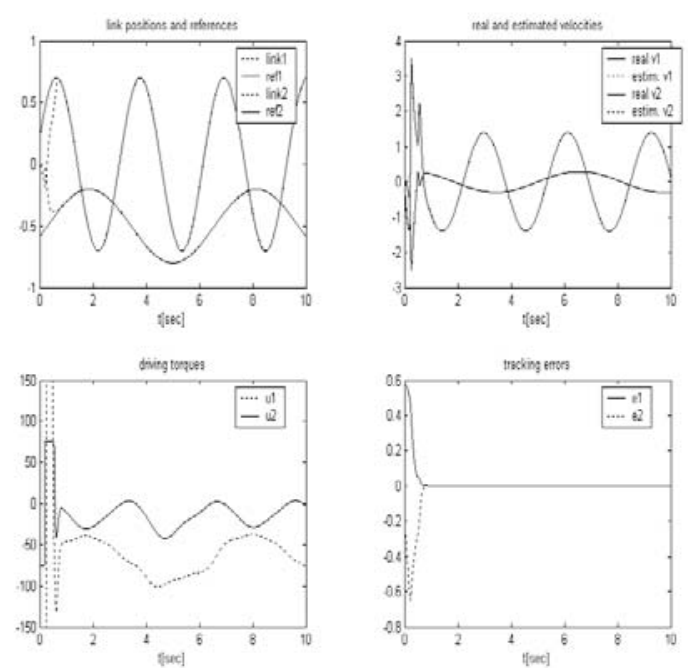

Fig.1. Closed loop robot response, smooth sliding observer and controller, parameterized tangent hyperbolic switching function $\mathrm{k}_{\mathrm{o}}=10, \mathrm{k}_{\mathrm{c}}=1$.

Fig. 1 shows the closed loop simulated manipulator response. Adaptive gains, smooth sliding observercontroller and time varying parameter have been introduced into the loop. Small parameter uncertainties $(10 \%)$ have been considered. Choosing $\mathrm{k}_{\mathrm{o}}>\mathrm{k}_{\mathrm{c}}$, a faster sliding observer convergence than that of the sliding controller is obtained. The response is chattering-free, despite the limitations introduced into the control input $\left(\left|\mathrm{u}_{1}\right| \leq 150 ;\left|\mathrm{u}_{2}\right| \leq 75\right)$. Even if, during sliding, the system evolves in a neighborhood of the corresponding sliding surface, the output tracking is achieved. In Fig. 2, the identification of the time-varying parameters $\mathrm{m}_{\mathrm{p}}(\mathrm{t})$ and the disturbance $\mathrm{d}(\mathrm{t})$ is shown. The reference signal is chosen to avoid the singularity of the matrix $\hat{\Phi}^{\mathrm{T}} \hat{\Phi}$. In order to compute the derivatives of the state estimate, the first order numerical difference is used. The phase lag does lead neither to instability and nor to fluctuation in the parameter estimates.

\section{CONCLUSIONS}

A robotic manipulator closed loop control with adaptive gains, smooth variable structure observercontroller and time varying parameter identification has been designed and tested by simulation. The output tracking and the robustness w.r.t. uncertainties and external disturbances are improved by the use of parameterised switching functions with gains adaptively updating. The parameterised $k$-tanh switching function assures an improvement or a complete elimination of chattering. An appropriate choice of the parameters in the observer and controller switching functions allows a faster convergence rate of the observer than that of the controller. The adaptively updated gains lead the system to output tracking with smooth transient response. With some conditions on the robot model,
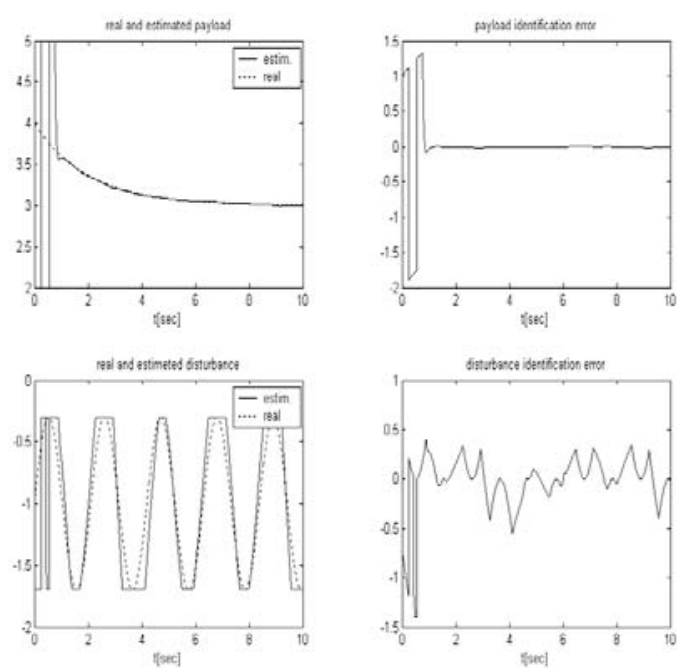

Fig.2. Closed loop, smooth sliding observercontroller, on-line time varying parameters and payload identification.

reference input and a priori information, the identifier of time-varying parameters converges. The error in the parameter estimates depends on the estimated state error and on the tracking error.

\section{REFERENCES}

Canudas de Wit, C., \& Slotine J. J. (1991). Sliding observers for robots manipulators; Automatica; 27(5): 859-864.

Filipescu, A, Dugard L., \& Dion J. M.(2003). Smooth variable structure observer-controller with adaptive gains. Application to robot manipulators control; European Control Conference, ECC03, Sep. Cambridge, U. K.

Khalil, H. K. (1996). Nonlinear systems. PrenticeHall, Englewood Cliffs, NJ.

Marino, R., \& Tomei, P. (1995). Non-linear control design. Prentice-Hall, Englewood Cliffs, NJ

Sanchis, R., \& Nijmeijer, H., (1998). Sliding Controller-Sliding Observer Design for Nonlinear Systems. European Journal of Control; 4; 208-234.

Slotine, J. J. \& Sastry, S. S., (1983). Tracking control of non-linear systems using sliding surfaces, with applications to robot manipulator. Int. J. Control, 38(2); 465-492.

Utkin V. I. (1992). Sliding modes in control and optimisation. Vol. 34. Berlin: Springer.

$\mathrm{Xu}$, J. X., \& Hashimoto, H. (1993). Parameter identification methodology based on variable structure control. Int. J. Control, 57(5); 12071220.

Xu, J. X., \& Hashimoto, H. (1996). VSS theorybased parameter identification scheme for MIMO systems, Automatica 39, 724-734.

Xu, J. X., Pan, Y. J., \& Lee, T. H. (2003). A VSS identification scheme for time-varyng parameters, Automatica 39, 724-734. 